\section{$\underset{\substack{\text { hommes } \\ \text { \& migrations }}}{ }$}

\section{Hommes \& migrations}

Revue française de référence sur les dynamiques

migratoires

$1324 \mid 2019$

Religion et discrimination

\title{
Lenka Hornakova-Civade, Une verrière sous le ciel
}

Paris, Alma éditeur, 2018, 260 pages, 18,50 euros

\section{Nihad Jnaid}

\section{Q OpenEdition \\ 1 Journals}

\section{Édition électronique}

URL : https://journals.openedition.org/hommesmigrations/8923

DOI : 10.4000/hommesmigrations.8923

ISSN : 2262-3353

\section{Éditeur}

Musée national de l'histoire de l'immigration

\section{Édition imprimée}

Date de publication : 1 janvier 2019

Pagination : 175-176

ISBN : 978-2-919040-44-5

ISSN : 1142-852X

\section{Référence électronique}

Nihad Jnaid, "Lenka Hornakova-Civade, Une verrière sous le ciel », Hommes \& migrations [En ligne], 1324 | 2019, mis en ligne le 01 janvier 2019, consulté le 08 janvier 2022. URL : http:// journals.openedition.org/hommesmigrations/8923; DOI : https://doi.org/10.4000/ hommesmigrations.8923 


\section{Lenka Hornakova-Civade Une verrière sous le ciel}

Paris, Alma éditeur, 2018, 260 pages, 18,50 euros.

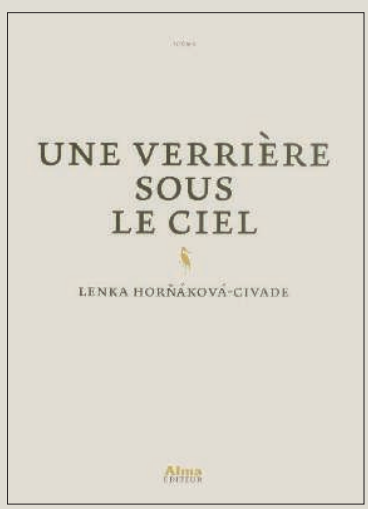

Gare de l'Est, Ana refuse de prendre le train qui la ramène à Prague après un séjour à Paris. Nous sommes en 1988, avec cette décision toute personnelle, cette jeune fille de 18 ans anticipe les événements qui vont sonner la fin du bloc de l'Est. Sans argent et livrée à elle-même, Ana cherche refuge au cimetière du Père-Lachaise. Point de départ de rencontres qui vont s'offrir à elle. Celle de Grofka, « une comète qui, régulièrement, reparaît dans le ciel», puis la rencontre du patron d'un café, Bernard, et de quelques clients; Jacob et Yacoub qui partagent le souvenir de la Méditerranée, mais aussi Eugène et Albert, le peintre. Devenue modèle pour ce dernier, Ana va passer des heures durant à contempler la verrière qui lui sert d'atelier. "La verrière, le lieu d'ailleurs, le plafond en verre pas très propre, en attente d'une grande douche; en levant le regard, aucune idée d'où nous nous trouvons, dans quelle gare, dans quel pays; et entre le ciel et nous, un filtre, un sfumato pour arranger les contours du monde.» Une note optimiste, une ouverture entre le dehors et le dedans, le monde extérieur et le monde intérieur.

Dans ce roman initiatique, Lenka Hornakova-Civade raconte la découverte de soi, l'exil et l'apprentissage de la vie: «Est ce que chaque personne trouve son propre poème? Ou même plusieurs? Pour les jours tristes, pour les jours heureux, pour les jours d'hésitation, d'amour, de doute et de colère? Je voudrais confier aux nuages voguant dans le ciel de France un message qu'ils transporteraient jusqu'à Prague, je voudrais que ce soient les nuages qui fassent le pont.»Pas à pas, de souvenir en découverte, Ana se métamorphose, se confronte aux réalités et tente de construire une nouvelle vie. "Les pensées viennent, tourbillonnent en spirale, en rond, se mordent, s'entrelacent, s'envolent, puis réapparaissent de nulle part, m'attrapent par surprise, les idées se métamorphosent en figures, se confondent, donnent naissance à d'autres, loufoques, et pourtant tout à fait crédibles.»

Divisé en trois livres, en majuscules dans la table des matières, «Au commencement il y avait le silence», "La saison des fleurs» et «Le recommencement», le roman s'achève sur une ouverture «Lignes de suite»: «Voilà (mes) quelques ports d'attache, les points de départ d'un roman. Peu importe quelle sera la première phrase de mon prochain texte, de la nouvelle, d'un roman, d'un récit. Il s'ouvrira tout au moins dans ma tête, par cette formule magique qui crée les mondes: il était une fois...»

Ana observe, écoute et découvre une nouvelle langue, celle de l'image: "D'un cerisier à l'autre, de l'arbre parisien méconnu à celui de la colline de Petřin, dans la cerisaie sur le chemin de la gare de banlieue pragoise, je me balade. Mon unique certitude: une autre langue grandit en moi, et en même temps, de plus en plus, j'ai l'impression de penser en images. » Même les liens difficiles avec sa famille et sa vie d'autrefois finissent par constituer une source de force: "Je m'y réfugie tel un escargot dans sa coquille, pas pour fuir, c'est déjà fait, mais pour y puiser, comme dans une source.»

Celle qui a forcé son destin se pose des questions sur sa vie d'avant, sa vie du moment et son devenir. "L'image, un terrain neutre, un refuge pour l'idée qui doit à la fin être prononcée. Un film défile devant mes yeux. Celui de ma vie d'avant, ailleurs, je n'ose pas dire chez moi, je ne sais plus ce que cela veut dire. Comme maintenant. Le jardin de mon père, placé au milieu de la rue devant moi n'a pas de langue, c'est une réalité que je vois. Si jamais je voulais la partager il me faut les mots. Je jalouse Albert, il a le trait, la ligne sur un champ blanc, le moyen d'expression universel le plus simple.» Ana s'initie à l'art et à la politique, apprend une nouvelle langue et 
une nouvelle culture. Une façon de goûter à la liberté et de tester ses limites.

Ce récit est celui d'un regard croisé: celui du peintre sur le corps de son modèle, Ana, et celui d'Ana sur elle-même. Un regard qui dépasse le corps et ses contours et questionne l'art et la poésie pour trouver des réponses. «Puis-je me défaire de la manière de regarder qu'on m'a inculquée dès l'enfance? Suis-je capable de voir la beauté, si toutefois elle existe?»

Le monde d'Ana se construit et seul son choix final, suspense, questionne l'aboutissement de cette aventure. Poésie, photo et peinture servent de vecteur de décryptage et d'assemblage de ce qu'est la vie d'Ana. Une vie racontée comme on raconte un tableau.

N.J. 